\title{
Gender Differences in Climate Change Adaptation Strategies in Maize-Legume Based Farming System in Ethiopia
}

\author{
Rehima Mussema Chilot Yirga \\ Ethiopian Institute of Agricultural Research
}

\begin{abstract}
Climate change is considered one of the most challenging current Ethiopian issues. Adaptation strategies are important to deal with climate change. The study assessed farmers' adaptation strategies of climate change and identified their determinants. The survey was taken 2065 households in 2013 from SIMLESA, and DIIVA projects data considering Maize-Legume Based Farming System in Amhara, Oromiya, and SNNP and Benshangul Gumuz regions of Ethiopia. Six adaptation strategies (crop rotation, intercropping, SWC, stubble, planting trees and mulching) were considered as dependent variables; all strategies are found to be dependent on each other suggests to use MVP. Climate adaptation strategies of MHH and FHH were different that might be due to access to resources, skill, and knowledge, hence, MVP analysis was used for the entire sample and FHHs separately. HHH characteristics, gender role, availability of resource and access to service were organized as explanatory variables. The result of the marginal effect of the explanatory variables in the whole sample indicated that MHHs had more probability to use stubble and SWC than FHHs. The education level of HHHs enhanced to use stubble and SWC and negatively associated with mulching. Old farmers were not convinced to use stubble; because the old might not see the benefit of the new strategy. These need designing policies to make gender-responsive, training based and demand-driven adaptation strategies. Due to gender roles and responsibilities, the availability of men and women labour affected different adaptation options in different ways. Hence keeping social norm and values, and farmers' capability and interests are important to improve the specialization and sustainability of adaptation options. Men and women labour were less likely to participate in tree planting by fear of birds attack; this suggests promoting tree planting with chopping and trimming the trees during crop planting and maturity period. Resource ownership (farm size, livestock, oxen and asset value) affected adaptation options in different ways; policy interventions suggest providing location-specific, affordable and appropriate adaptation options for the best chance of success and sustainability of the strategies. Access to membership in women groups, improved varieties, and extension affected different adaption options in different ways. These results underline the need to strengthen and support extension service and social groups to include appropriate adaption strategies as one of the technology packages. Access to market enabled to choose adaptation options suggests strengthening and establishing an early warning system at the village level to forecast and farmer's preparedness. Living in different regions suggests providing agro-ecology and research-based adaptation options to manage risks and maximize opportunities from climate change. Gender differential adaptation strategies were observed in the farming system. FHHs more adopted stubble, crop rotation, and SWC than MHHs did. Due to a long time using age and education of FHHs significantly and negatively affected crop rotation. Due to gender roles, more women labour discouraged to engage in SWC. Policies should give better attention to investing and availing women-specific alternative adaptation options. Collecting firewood is the responsibility of women; hence being a member of women in cooperative negatively affected stubble. There is a need to avail of alternative options or renewable energy sources. FHHs with more farmland less likely to choose SWC due to high cost and different characteristics of plots, however FHHs with high assets value able to choose stubble and SWC because they can cover related costs. The policy should be designed extension system to avail appropriate and affordable options. Using more improved crop variety increases the probability of women farmers' choosing SWC; the government requires improving the number of packages by including appropriate climate adaptation options.
\end{abstract}

Keywords: Climate adaptation, gender, mulch, stubble, MVP

DOI: $10.7176 / \mathrm{JEES} / 10-6-02$

Publication date:June $30^{\text {th }} 2020$

\section{Introduction}

\subsection{Background}

Africa is one of the most vulnerable continents to the current climate variability with a strong economic effect (Hassan and Nhemachena, 2008). Like many African countries, Ethiopia also vulnerable to climate change (FAO, 2014). Climate change causes to varying weather conditions and rainfall patterns that affect agriculture and food production in complex ways. FAO (2018) reported that about $26 \%$ of the total damage and loss of agriculture caused by climate-related disasters in developing countries. This is particularly right for Ethiopia, where more than $85 \%$ of the population relies on rain-fed agriculture. Ethiopian economy mostly depends on agriculture that highly sensitive to climate change; therefore, any effect on agriculture significantly affects the national economy.

Hence to protect the Ethiopian economy from climate risk and to enhance agricultural production and food 
security, farmers require adjustments and take different actions. Adoption of climate change adaptation options assumed to minimize the adverse effects of climate change in the economy (Akinnagbe and Irohibe, 2014). Without taking adaptation strategies, climate change will seriously place food production at risk in most regions of Ethiopia (FAO, 2014).

According to FAO (2012) report, climate adaptation is the ability to adjust climate change to control potential damage and take advantage of opportunities from climate change. There is a range of adaptation options that comprise measures of prevention as well as measures of adopting a change in traditional agriculture in Ethiopia: soil and water conservation (SWC), intercropping, fallowing, mulching, contour plowing, crop rotation, conservation tillage, irrigation, agroforestry, changing planting date, etc. (Amisalu, 2018; Gebre et al., 2015; Wondimagegn and Lemma, 2015; Deressa et al., 2011).

Rural men and women experience climate variability differently and cope in diverse ways. Due to gender roles and responsibilities, access and control of resources men and women are differently affected by climate change and manage climate change variability (Baćanović and Murić., 2018). Women play a significant role in agricultural activities (land preparation, hoeing, weeding, harvesting, threshing, transportation, etc.) and food processing. However, they face many obstacles to access productive inputs, assets, and services; these obstacles not only lead to low productivity (UNDP, 2012) but also increase their vulnerability to climate change. Hassan and Nhemachena, (2008) verified that female and male-headed households differ significantly in their capacity to adapt to climate change because of differences in access to resources, education and other institutional factors (access to credit, technology, and input) among them.

Aguilar et al., (2014) reported that overall 23\% of gender differential in agricultural productivity is estimated due to unequal access to resources, training, land qualities, etc. in Ethiopia. As a result, the impact of climate change in agricultural production has the potential to cause severe food shortages in Ethiopia, particularly rural women may most be affected. Further, there is extensive literature on adaptation to climate change in Ethiopia (Deressa et al., 2011: Aemro et al., 2012; Aschalew, 2014; Seid et al., 2016). However, these studies did not generate gender-disaggregated information related to climate change, but their empirical approaches only consider comparing male- and female-headed households as a single explanatory variable. Therefore, as of now, there is limited empirical evidence on how gender at the inter- and intra-household level influences the adaptive capacities of men and women farmers. Therefore understanding the adaptation options and the determinant factors of men and women farmers separately will provide information for appropriate climate adaptation policy intervention.

\subsection{Statements of the problem}

Climate change adaptation strategy has the potential to minimize risk from climate change effect; therefore, adaptation strategies are common and practiced by smallholder farmers in Ethiopia. Hence there are empirical studies conducted in different location of the country: Aemro et al., (2012) in Babilie District, Aschalew, (2014) in Adola Rede Woreda, Seid et al., (2016) in Assosa district, Abrham et al., (2017) in Central Rift Valley, Abayineh and Belay, (2017) in Muger Sub-Basin of the Upper Blue-Nile Basin, and Amogne, et al., 2018 northcentral Ethiopia. However, these studies are too aggregated to exactly indicate local climate change and variability impacts at different time, and farmers' adaptation strategies at a specific location. Therefore it is important to study adaptation strategies of maize- legume-based farming systems in Ethiopia.

In countries most dependent on rain-fed agriculture and natural resources, poor rural women, who have fewer assets and less decision-making power than men, are even more exposed for climate risk (IFAD, 2015); this is true for Ethiopian women farmers who estimated half of the rural population depend on rain-fade agriculture; particularly poor women experience chronic food insecurity (UNDP, 2012).

Women are usually more vulnerable to climate change impacts than men (IFPRI, 2014; Tesfamichael, 2016) due to the roles and responsibilities assigned to them by society. Adaptation decisions are gender-sensitive, some adaptation strategies are chosen by men while others are favored by women (Amogne et al., 2018). Therefore adaptation options to climate change are different among men and women due to their different social and economic roles, and responsibilities as well as existing inequalities in skill, access to resources and decisionmaking power. Women are still among the most disadvantaged groups of society and are particularly vulnerable to current and future climate change and food insecurity (UNDP, 2017). Therefore considering gender issues is important in climate change because the activity of rural female farmers is essential for improving agricultural productivity and ensuring food security as well as tackling the risks of climate change.

Except for few gender-related adaptation studies of farm households in a specific location (Biniam, 2017; Tesfamichael, 2016; Gutu, 2015, Nabikolo et al., 2012; Tibesigwa et al., 2015; Owombo et al., 2014), gender differential climate change adaptation is not well known in Maize-Legume farming system. Therefore, all aspects related to climate change need to generate gender-disaggregated information for gender-responsive policy intervention. 


\subsection{Research Questions/hypotheses}

$>$ What are the climate adaptation strategies used by farmers in the Maize-Legume farming system?

$>$ What are gender-sensitive or gender-specific adaptation options?

$>$ What are the determinant factors for adaptation strategies to climate change used by male-headed households (MHH) and female-headed households (FHH)?

$>$ How are these factors influencing farmers' climate change adaptation strategies?

\subsection{The objective of the study}

The overall objective of the study is to examine the adaption strategies of farmers in Maize-Legume farming areas in Ethiopia. The specific objectives are:

1. To identify gender differential adaption strategies to climate change, and

2. To identify the determinant factors of adaptation options among entire farm households and female-headed households, separately.

\subsection{Scope and limitation of the study}

This study mainly used the 2013 survey which is collected by Sustainable Intensification of Maize and Legume System for Food Security in Eastern and Southern Africa (SIMLESA) and Diffusion and Impact of Improved Varieties in Africa (DIIVA) form Maize-Legume farming system in Ethiopia: Amhara, Oromiya, SNNP and Benshangul Gumuz regions. The survey conducted from 2455 farm households' however the study used only 2065 households' data who have the necessary information for the study.

\section{Methodology}

\subsection{The study areas}

Cross-sectional data were drawn from SIMLESA and DIIVA projects that collected in 2013 from Amhara, Oromiya and SNNP and Benshangul Gumuz regions of Ethiopia. The study areas are considered to be the most suitable areas to study climate change adaptation practices and generate gender-disaggregated information in maize and legume farming system as they lie in different regions and are inhabited by different communities, different gender roles, and ethnic groups in Ethiopia. Most (60\%) of sampled households were located and drawn from Oromia, followed by SNNP (22\%), Amhara (14\%) and Benshangul Gumuze (4\%). Gendered distribution had a significant difference in Benshangul Gumuze region that FFH (7\%) is more than MHH (3\%) (Table 1).

Table 1. Gender differential in regional distribution of sampled farmers

\begin{tabular}{lcccc}
\hline & MHH & FHH & Total & Chi $^{2}\left(\chi^{2}\right)$ \\
Description of variables (\%) & $(1,918)$ & $(147)$ & $(2,065)$ & \\
\hline Oromia & 61 & 56 & 60 & 0.9439 \\
SNNP & 22 & 22 & 22 & 0.0120 \\
Amhara & 14 & 15 & 14 & 0.1370 \\
Benshangul & 3 & 7 & 4 & $4.3525^{* *}$ \\
\hline
\end{tabular}

** Significant at 5\%

$\%$ within sex of the $\mathrm{HHH}$

\subsection{Data collection and sampling technique}

Data was collected with the use of a structured questionnaire. Enumerators hired and trained to translate local languages. The sampling of the household survey followed a three-stage stratified random sampling. In the first stage, from all regions, 22 zones are identified and from each zone total of 38 woredas were selected randomly. In the second stage, enumeration areas and rural Kebeles (RKs) were randomly selected from each woreda. In the third stage, sample households were randomly selected from the list provided by the RK offices.

\subsection{Empirical Analysis}

The study used both descriptive statistics and Econometric analysis. The study used descriptive statistical tools such as mean, percentages, frequencies and standard deviations to summarize and categorize sampled households' information. Crosstabs, t-test $\mathrm{Chi}^{2}\left(\chi^{2}\right)$ tests are employed to compare means between $\mathrm{MHH}$ and FHHs.

There are alternative econometric analyses that can be used for adaptation options. Univariate techniques such as probit and logit analysis for discrete choice dependent variables to model each of the adaptation measures individually as functions of the common set of explanatory variables. Farmers might use a combination of adaptation options as complementary. However failure to recognizing the common factors that the univariate technique ignores potential correlations among the unobserved disturbances in adaptation measures, and this may lead to statistical bias and inefficiency in the estimates (Lin et al., 2005; Golob and Regan, 2002). A MNL model is another alternative to a complicated multivariate model with the six endogenous discrete choice variables. The shortfall MNL is that interpretation of the influence of the explanatory variables on choices of each of the number 
of original separate adaptation measures is very difficult and the usefulness of MNL is limited by the property independence of irrelevant alternatives (IIA). The IIA means that all else being equal, a person's choice between two alternative outcomes is unaffected by what other choices are available (Cheng and Long, 2007).

Therefore this study used multivariate Probit (MVP) to overcome the shortfalls of using the univariate and MNL choice techniques. The choice of the model was based on recent adaptation studies experiences (Hailemariam et al., 2019; Adjaye et al., 2016). Multivariate Probit is simultaneously model that influence of a set of explanatory variables on each of the different adaptation measure while allowing the unobserved and error terms to be freely correlated (Green, 2003). A MVP model is a generalization of the Probit model used to estimate several correlated binary outcomes jointly. The likelihood of adoption of adaptive measures which is the dependent variable that has been determined by identifying adopters and non-adopters of specific adaptive strategies adopted by men and women farmers in the study areas. A MVP model assumes that each subject has M distinct binary responses and a matrix of covariates that can be any mixture of discrete. The climate adaptation strategies, $Y_{i}$, (stubble, SWC, intercrop, mulch, tree planting, and crop rotation) are dependent variables. Especially, $\mathrm{Y}_{\mathrm{im}}=\left(\mathrm{Y}_{\mathrm{i} 1}\right.$, $\mathrm{Y}_{\mathrm{i} 2}, \mathrm{Y}_{\mathrm{i} 3}, \mathrm{Y}_{\mathrm{i} 4}, \mathrm{Y}_{\mathrm{i} 5}$, and $\mathrm{Y}_{\mathrm{i} 6}$ ) denote the $\mathrm{M}$ dimensional vector of observed binary 0 and 1 responses on the $\mathrm{i}^{\text {th }}$ subject, $\mathrm{m}=1, . ., 6$ and let $\mathrm{Z}_{\mathrm{i}}=\left(\mathrm{Z}_{\mathrm{i} 1}, \ldots, \mathrm{Z}_{\mathrm{i} 6}\right)$ denote an $\mathrm{M}$-variate normal vector of latent variables. The general formulation of the MVP model is

$Z^{*}{ }_{i m}=\beta{ }_{m} X_{i m}+\mu_{\text {im }}$,

$\mathrm{m}=1, \ldots, \ldots . \mathrm{M}$

where $Z^{*}{ }_{\mathrm{im}}$ is a latent participation variable for household $\mathrm{i}, \mathrm{X}_{\mathrm{i}}$ is the independent variable, $\mu_{\mathrm{i}}$, is an $\mathrm{M} \times 1$ vector of residual error, assuming that error terms $\mu_{\mathrm{i} 1}, \mu_{\mathrm{i} 2}, \mu_{\mathrm{i} 3} \mu_{\mathrm{i} 4}, \mu_{\mathrm{i} 5}$, and $\mu_{\mathrm{i} 6}$ are independent. The study then assumes that these error terms are jointly normally distributed with a mean zero and covariance matrix $\Sigma$. That is $\left(\mu_{\mathrm{i} 1}, \mu_{\mathrm{i} 2}, \mu_{\mathrm{i} 3} \mu_{\mathrm{i} 4}\right.$, $\mu_{\mathrm{i} 5}$, and $\left.\mu_{\mathrm{i} 6}\right) \sim \operatorname{MVN}(0, \Sigma)$ with the six for the entire population and three for FHH variances assumed equal to 1 (see equation 2). A univariate approach ignoring the potentially none zero off-diagonal elements in $\Sigma$ will produce inconsistent coefficient estimates, where the correlation across the error terms exists (Maddala, 1983).

$\left(\begin{array}{l}\mu_{1} \\ \mu_{2} \\ \mu_{3} \\ \mu_{4} \\ \mu_{5} \\ \mu_{6}\end{array}\right) \sim N_{M}\left(\begin{array}{l}0 \\ 0 \\ 0 \\ 0 \\ 0 \\ 0\end{array}\right),\left(\begin{array}{ccccccc}1 & \rho_{12} & \rho_{13} & 1 \rho_{14} & \rho_{15} & \rho_{16} \\ \rho_{12} & 1 & \rho_{23} & \rho_{24} & \rho_{25} & \rho_{26} \\ \rho_{13} & \rho_{32} & 1 & \rho_{34} & \rho_{35} & \rho_{36} \\ \rho_{14} & \rho_{43} & \rho_{34} & 1 & \rho_{35} & \rho_{46} \\ \rho_{15} & \rho_{25} & \rho_{35} & \rho_{45} & 1 & \rho_{56} \\ \rho_{16} & \rho_{26} & \rho_{36} & \rho_{46} & \rho_{56} & 1\end{array}\right)$

where $\rho$ (rho) represents the pair-wise correlation coefficient of the error terms to be estimated in the model. The relationship betweek $\mathrm{Y}_{\mathrm{im}}$ and $\mathrm{Z}^{*}{ }_{\mathrm{im}}$ in the MVP model is given by

$\mathbf{Y}_{\mathrm{im}}=\mathbf{1}$ if $\mathbf{Z}^{*}{ }_{\mathrm{im}}>\mathbf{0}$

0 Otherwise $\}$

Assuming that $Z^{*}$ is distributed per a normal distribution: $Z^{*} \sim N\left(\rho_{i}, 1\right)$. This leads to a "Probit" model of choice where the probability of participation, $\mathrm{P}$, is specified as:

$\mathbf{P}\left(\mathbf{Y}_{\mathrm{i}}=\mathbf{1} / \boldsymbol{\beta}, \Sigma\right)=\boldsymbol{\Phi}\left(\mathrm{Z}_{\mathrm{i}}^{*}\right)$

$\mathrm{Z}_{\mathrm{i}}^{*} \sim \mathrm{N}\left(\mathrm{X}_{\mathrm{i}} \beta, \sum\right)$

where $\Phi$ is the Probit link which denotes the CDF of the normal distribution. Here, $\beta=\left(\beta^{-{ }^{*}}{ }_{1} \ldots \beta^{-}{ }_{\mathrm{T}}\right)$ is a $\mathrm{p} \times \mathrm{M}$ matrix of unknown regression coefficients, $\sum$ is the $\mathrm{M} \times \mathrm{M}$ correlation matrix of $\mathrm{Z}_{\mathrm{i}}^{*}$. The basic specification is a Probit model (3) which captures the likelihood that a household has adaptation options for climate change. To give operational meaning to the above condition of participation, it is assumed that the latent variable is a stochastic function of individual adaptation options characteristics. For the participation decision model intercepts:

$\alpha_{\mathrm{im}}=\mathrm{w}_{\mathrm{i}} \psi_{\mathrm{m}}+\mathrm{v}_{\mathrm{im}}$

where $\mathrm{w}_{\mathrm{i}}$ is a vector of household socioeconomic variables that affect participation options, and $\Psi$ is parameter vector relating household i's characteristics to its intrinsic preference for participation option ' $\mathrm{m}$ ' in the conditional participation decision model.

The model estimated using MSL ('GHK' simulator). The GHK simulator exploits the fact that a multivariate normal distribution function can be expressed as the product of sequentially conditioned univariate normal distribution functions, which can be easily and accurately evaluated. The objective of this simulation study is to examine the performance of large-sample standard errors.

Cappellari and Jenkins (2003) advised that for small sample sizes, estimates may be sensitive to the choice of seed value unless random draws is large that is there would remain the issue of finite sample bias. The large random draws provide good estimates of the underlying model (not only of the regression coefficients but also of the correlation matrix). Therefore, MVP estimates are obtained by MSL with the mvprobit command in STATA with 40 random draws for the entire sample $(\mathrm{N}=2065)$ and 100 random draws for $\mathrm{FHH}(N=147)$.

Variables included in the analysis

Dependent variables for all samples (stubble, SWC, intercropping, mulching, trees planting and crop rotation) and for FHH (stubble, crop rotation, and SWC) are summarized in Table 2. 
Stubble is the cut stalks of cereal plants left sticking out of the ground after the grain is harvested. Stubble tillage is a type of conservation tillage where farmers retain the stubble on soil's surface and mix the stubble with the soil surface with rough tillage right after harvest to avoid grazing by livestock as well as to facilitate decomposition of organic materials before the next copping season starts (Menale et al., 2008). Mulching is the process of covering the soil surface around the plants to create good-natured conditions for crop growth. The mulching option helps to reduce soil evaporation and maximum temperatures in the soil surface layers and to increase water infiltration, soil porosity, and aggregate stability (Globalfood, 2014).

The explanatory variables that are assumed to affect the dependent variables are summarized in Table 3.

Table 3 Independent variables

\begin{tabular}{llll}
\hline Variables & Description & Characteristics & Values \\
\hline Sex & Sex of HH & Dummy & $1=$ Male, 0= Female \\
lnage_hd & Age of HHH & Continuous & Year \\
lneduc_hd & Education of HHH & Continuous & Years of schooling \\
lnmalelabor- & Men labour & Continuous & adult equivalent man hour \\
lnfemalelabor & Women labour & Continuous & adult equivalent man-hour \\
Womenmember & women coop. member & Dummy & $1=$ Yes, 0= Otherwise \\
Lnfarmsize & Farm size & Continuous & Mean hectares \\
lntlu & Livestock holding & Continuous & TLU \\
Lnnumboxen & Number of oxen & Continuous & Number \\
Lnassetvalue & Asset value & Continuous & Birr \\
lnimprovedvar & lmproved varieties & Continuous & Number of varieties used \\
Lnnumbext & Access to Extension & Continuous & Number of days in a year \\
lndstmnmkt & Market distance & Continuous & km \\
Oromia & Oromia region & Dummy & $1=$ Oromia region, 0 otherwise \\
Bensha & Benshangul G. region & Dummy & $1=$ Benshangul G., 0 otherwise \\
SNNP & SNNP region & Dummy & $1=$ SNNP region, 0 otherwise \\
\hline
\end{tabular}

\section{Result and Discussion}

\subsection{Descriptive statics}

\subsubsection{Adaptation Strategies}

The major adaptation strategies by sampled MHH and FHH farmers presented in (Table 4). The results showed that most (92\%) sampled households used crop rotation, followed by inter-cropping (50\%), SWC (44\%) and stubble $(30 \%)$ as adaptation strategies. However, few farmers used planting trees and mulching to adapt to climate change. These results revealed that farmers used a combination of different adaptation strategies to minimize climate change risks. Choosing adaptation options between men and women determined by their specific needs and their access to resources. Therefore gender difference was found at a 10\% significance level in intercropping; FHH used more intercropping than MHHs. Similarly, 1\% significant level gender differences were observed on SWC and stubble options; FHH more chose these adaptation options than their counterpart.

Table 4. Gender differential in Climate change adaptation options

\begin{tabular}{lllll}
\hline & MHH (\%) & FHH (\%) & Total (\%) & Chi $^{2}\left(\chi^{2}\right)$ \\
Description of variables (\%) & $(\mathrm{N}=1,918)$ & $(\mathrm{N}=147)$ & $(\mathrm{N}=2,065)$ & \\
\hline interrot -Rotation & 90 & 92 & 92 & 0.4395 \\
intercrop - Intercropping & 42 & 50 & 50 & $3.5691^{*}$ \\
swcuse - SWC & 24 & 45 & 44 & $23.3532^{* * *}$ \\
Stuble- Stubble & 16 & 31 & 30 & $14.3082^{* * *}$ \\
trees:-Planting trees & 1 & 2 & 2 & 0.3601 \\
Mulch- Mulching & 1 & 1 & 1 & 1.0951 \\
\hline
\end{tabular}

*** and $*$, significant at $1 \%$ and $10 \%$, respectively

$\%$ within sex of the $\mathrm{HHH}$

\subsubsection{Household characteristics}

Characteristics of the household are summarized in (Table 5). Except for women's labour availability in a household, the tests confirmed that there were significant differences in household characteristics of $\mathrm{MHH}$ and FHH. The results revealed that most of the farmers $(93 \%)$ were $\mathrm{MHH}$. The mean age of the HHH was 42 years, relatively FHH were older (44.41) than MHH (41.92) years. The average education of the HHH was 2.99; FHH had an average of 1.33 years of formal education which is less than MHH (3.12). The average household size in the sample was 6.82; the average family size in FHH was (5.17 people) less than MHH (6.95 people). The average male labour (equivalent to man-hour) spend on agricultural activities (land preparation, planting, weeding, harvesting, etc.) in the household was 82 man-hour; man-hour in FHH (59) was less than in MHH (84). Average women labour (equivalent to man-hour) in the household was 32.68. 
Table-5. Gender differential characteristics and gender contribution in the Households

\begin{tabular}{lcccc}
\hline Description of variables & $\begin{array}{c}\text { MHH } \\
(\mathrm{N}=1,918)\end{array}$ & $\begin{array}{c}\mathrm{FHH} \\
(\mathrm{N}=147)\end{array}$ & $\begin{array}{c}\text { Total } \\
(\mathrm{N}=2,065)\end{array}$ & t-test/Chi $\left(\chi^{2}\right)$ \\
\hline sex of HHH (percent of the hhh) & 93 & 7 & 100 & $2.1 \mathrm{e}+03 * * *$ \\
age_hd (age of HHH) & 41.9202 & 44.4082 & 42.0973 & $2.3244 * *$ \\
educa_Cat (education of HHH) & $(12.6229)$ & $(10.8670)$ & $(12.5201)$ & \\
& 3.118874 & 1.3265 & 2.9913 & $-6.4059 * * *$ \\
famlysize (family size) & $(3.3091)$ & $(2.6949)$ & $(3.3010)$ & \\
& 6.9463 & 5.1769 & 6.8203 & $-8.3512 * * *$ \\
malelabor- Male labour & $(2.5232)$ & $(2.2430)$ & $(2.5487)$ & $-3.3583 * * *$ \\
femalelabor- Female labour & 84.0101 & 59.3600 & 82.2553 & \\
& $(87.7237)$ & $(53.8567)$ & $(85.9810)$ & 0.1703 \\
\hline
\end{tabular}

\subsubsection{Resource ownership}

Ownership of resources is an indication of the wealth status of farmers. As indicated in Table 6 except asset value, there were significant differences in resource ownership (land, livestock, and oxen) at 1\% level between MHH and FHH. The average landholding size of the farmers was 2.25 hectares. The average landholding of $\mathrm{MHH}$ (2.28 hectares) was greater than FHH's (1.82 hectares). The farmers had an average of 6.94 TLU; however, MHH's livestock holding (7.17) was greater than FHH's (3.98). The farmers had an average of one pair oxen (2.12); MHH had more oxen (2.19) than FHH (1.18). The average estimated asset value (farm implement, cart, household furniture, radio, TV, jewelry, etc.) of sampled households was Birr 26,722.23.

Table 6 Gender Differential in resource ownership, access to service and technology

\begin{tabular}{|c|c|c|c|c|}
\hline Description of variables & $\begin{array}{c}\text { MHH } \\
(1,918)\end{array}$ & $\begin{array}{l}\text { FHH } \\
(147)\end{array}$ & $\begin{array}{c}\text { Total } \\
(2,065)\end{array}$ & t-test \\
\hline Farmsize (land/ ha) & $\begin{array}{c}2.2821 \\
(2.0859)\end{array}$ & $\begin{array}{c}1.8244 \\
(1.4705)\end{array}$ & $\begin{array}{c}2.2495 \\
(2.0513)\end{array}$ & $-2.6108 * * *$ \\
\hline tlu (livestock in TLU) & $\begin{array}{c}7.1678 \\
(6.1823)\end{array}$ & $\begin{array}{c}3.9831 \\
(4.2983)\end{array}$ & $\begin{array}{c}6.9411 \\
(6.1218)\end{array}$ & $-6.1323 * * *$ \\
\hline Numboxen (oxen number) & $\begin{array}{c}2.1882 \\
(2.4458)\end{array}$ & $\begin{array}{c}1.1769 \\
(1.4744)\end{array}$ & $\begin{array}{c}2.1162 \\
(2.4036)\end{array}$ & $-4.9444 * * *$ \\
\hline Asset value (asset value/Birr) & $\begin{array}{c}26,213.50 \\
(51,109.30)\end{array}$ & $\begin{array}{c}33,359.83 \\
(132,264.00)\end{array}$ & $\begin{array}{c}26,722.23 \\
(60,555.30)\end{array}$ & 1.3793 \\
\hline numbext (contact days in a year) & $\begin{array}{c}85.5662 \\
(86.17868)\end{array}$ & $\begin{array}{c}73.4900 \\
(89.3711)\end{array}$ & $\begin{array}{c}84.7065 \\
(86.4433)\end{array}$ & -1.6331 \\
\hline improvedvar (No. of improved crop varieties) & $\begin{array}{c}5.6241 \\
(2.8772)\end{array}$ & $\begin{array}{c}4.4558 \\
(2.4529)\end{array}$ & $\begin{array}{c}5.54 \\
(2.8644)\end{array}$ & $-4.7912 * * *$ \\
\hline Womenmember $(\%)$ & 17 & 24 & 18 & $4.3164 * *$ \\
\hline Dstmnmkt (nearest market distance, $\mathrm{km}$ ) & $\begin{array}{c}0.4304 \\
(1.2524)\end{array}$ & $\begin{array}{c}0.6796 \\
(3.0439)\end{array}$ & $\begin{array}{c}0.4481 \\
(1.4548)\end{array}$ & $2.0030 * *$ \\
\hline
\end{tabular}

As indicated in (Table 7) there were significant differences in access to services between MHH and FHH. Sampled farmers used an average of 5.54 improved crop varieties in 2013; however, FHH used less (4.46) number of varieties than $\mathrm{MHH}$ (5.62). On average 18\% of farm household members were members of women group. However, women from FHH had more opportunities (24\%) to join in the women group than wives/women in MHH (17\%). The farmers need to go an average of $0.44 \mathrm{~km}$ to reach the nearest market. However, FHH got a market after traveling more $\mathrm{km}(0.68)$ than $\mathrm{MHH}(0.43)$.

\subsection{Econometric results}

\subsubsection{Empirical Findings}

Participation decisions are affected by random shocks of household adaptation options. The estimated correlation of the error terms $(\rho)$ is significantly different from zero. The result in (Table 8 and 9) indicated that the nonzero censoring points are positive signs suggest the adaptation options participation decisions are influenced in the same direction by random shocks. For entire sampled farmers the lower censoring and upper threshold are at $\rho$ intercrop*stuble $(0.1065)$ and $\rho$ interrot*intercrop (0.877), respectively. For FHH the lower censoring threshold is at $\rho$ interrot*stuble $(0.544)$ and the upper threshold is at $\rho$ swcuse*interrot $(0.855)$. These results confirmed that climate adaptation option decisions are not statistically independent; therefore, using univariate may generate inefficient parameter estimates.

The variance-covariance matrices of the cross-equation error terms were estimated and the null hypotheses 
were zeros. The models use independently may generate biased and inconsistent coefficients. However, eight from entire sampled farmers' participation and two from FHH participation covariate values are significantly different from zero, indicating the covariates have a significant impact on participation options; these confirmed that estimating the consistency and efficiency of the model. Based on the likelihood ratio (LLR) test, model adequacy indicates that LLR and Wald statistics are 329.606 and 501.07 with a high significance level of $1 \%$ probability for all sampled farmers. The LLR and Wald statistics of FHH are 160.3037 and 89.36 with high significance at $1 \%$ level. These indicating regressions of best fit.

\subsubsection{Result of the MVP model for the entire population}

Multivariate probit regression results presented in Table 8. To generate intra-household information four gendersensitive variables included in the whole sample: sex of $\mathrm{HHH}$, availability of male and male labour, and membership of women group in the household.

Gender of Household Head (sex): Gender difference was observed in the stubble and SWC adaptation options. The MHHs are significantly and more likely to select stubble and SWC at 1\% level as compared to FHH. The result indicates that male headship increased the likelihood of adaptation of stubble and SWC by $11.24 \%$ and $18.29 \%$, respectively. Men usually getting information about these adaptation options and access to resources to deal with the consequence of climate change compared to FHH. This result is in line with several findings (Abrham, et al., 2017, Abayineh and Belay, 2017, Birtukan and Abraham, 2017. Federica et al., 2016; Adjaye et al., 2016; Solomon et al., 2014; Belaineh et al., 2013; Deressa, et al., 2011; Negash, 2014) that MHH is often considered to be more likely to get information than their counterpart about climate change measures.

Age of household head (Ina'ge_hd). Age of HHH is considered as a proxy indicator of experience on climate adaptation. However, the age of the HHH significantly and negatively affected stubble at $5 \%$ level. A year increase in the age of $\mathrm{HHH}$ decreased the probability of choosing stubble by $7.22 \%$. This might be stubble is a new technique of climate-smart agriculture; older farmers did not see the performance of new technology and they were less confident than younger HHHs. This result is similar to the findings of various studies (Abrham, et al., 2017; Gebre et al., 2015) older farmer decreased the probability of choosing SWC and tree planting.

Education of household head (Ineduc_hd). Years of education of the HHH significantly and positively correlated with stubble at $1 \%$ level, and SWC at $10 \%$ level, however education of the HHH negatively correlating with mulching at a $10 \%$ level. The marginal effects show, a unit increase in the number of years of education of the $\mathrm{HHH}$ increased the probability of choice of stubble by $0.9 \%$ and SWC by $0.78 \%$. Education gives farmers ability to understand, and increase the likelihoods of capacity and willingness to accept stubble and SWC much faster than the less educated. Similar studies (Deressa et al., 2011; Gebre et al., 2015; Negash, 2014; Seid et al., 2016; Abrham et al., 2017) reported that a positive relationship between education and SWC in Ethiopia. However, a year increase in schooling led to decrease mulching by $0.04 \%$. It might be more educated farmers broaden alternative income; more likely to have additional off-farm activities than mulching to sustain an income in case agriculture fails.

Availability of male labour hour- equivalent to man hour (Inmalelabor): Some adaptation options require more labour; hence the availability of male labor is expected to contribute to labor-intensive adaptation options. Hence, the availability of male labour hour is positively associated with intercropping and crop rotation at $5 \%$ levels of significance. Increasing male labour hour, by one unit, increases the probability of adopting intercropping by $4.81 \%$ and crop rotation by $13.01 \%$. The result implies that large male labour minimizes the labor constraint of the household to do various labour intensive adaptation options: intercropping and crop rotation practices. This finding is in line with the argument that large family size is normally associated with a higher labor endowment that contributes to climate change adaptation (Birtukan and Abraham, 2016 Abrham et al., 2017). However, the availability of male labour hour is negatively associated with tree planting at $5 \%$ significance level. A unit increase in male labour hour in a family led to a decrease the probability of tree planting practice by $0.41 \%$. This is probably because farmers reluctant to plant by fearing birds' crop attacks in the farmland and can resort to other off-farm activities as a source of income to minimize risk from climate change.

Availability of female labour hour- equivalent to man hour (Infemalelabor): Women are engaging in all farming activities and can use adaptation options, however, due to some socio-economic and cultural taboos women may not participate in some activities. Women labour hour in the household significantly and positively associated with stubble and crop rotation at 1\% level. A unit increase in women labour hour would increase the probability of stubble by $2.46 \%$ and crop rotation by $6.73 \%$. However, women labour adversely affected both SWC and planting a tree at 5\% significant level. As a unit women labour hour increase would reduce the probability of choosing SWC and planting a tree by $0.1 \%$ and $7.2 \%$, respectively. While many cultures, traditions, have usually assigned some agricultural tasks to men and others to women might be given different roles and responsibilities, and cultural barriers hinder women to engage in SWC and planting a tree. This result is in line with the finding of (Seid et al., 2016) that the availability of large families reduced the probability of adoption of SWC.

Membership of women group in a household (womenmember): Membership in a social group can help to get information on climate adaptation options, hence membership of women cooperative is significantly and positively 
affected SWC practices at $1 \%$ level. Being a member in women cooperative increases the probability of adopting SWC practice by $11.28 \%$. The reasonable explanation of the result is interactions among farmers in women groups increase awareness, social capital formation, knowledge sharing and exchange of facts related to use SWC. The similar findings indicates that being membership in a social group adds skill and knowledge of climate adaptation options of small scale irrigation and SWC (Abayineh and Belay, 2017; Solomon et al., 2014). Farmers' groups are effective in disseminating technologies, building a sense of shared purpose, and enabling cooperative action in sustainable natural resources management and development (Rathgeber, 2011). However, membership in women groups significantly and negatively affected both inter-cropping and crop rotation at $5 \%$ level. Being in the women group decreases the probability of participation of intercropping by $8.16 \%$ and crop rotation by $18.32 \%$. This implies the women groups decreases the exposure of farmers' intercropping and crop rotation, and diversify income from other activities.

Land holding size (Infarmsize). Landholding is associated with greater wealth, the larger the farm, the farmers may opt for a combination of several adaptation strategies. Therefore the result indicated that the farm size of the household significantly and positively related to stubble and rotation at $10 \%$ and $1 \%$ level, respectively. The addition of one hectare of land would increase the probability of stubble by $3.05 \%$ and crop rotation by $26.02 \%$; these adaptation options may less costly and require less chemical to manage soil fertility. This is in line with the argument (Aschalew, 2014; Ayuya et al., 2012) that farmers with large farm sizes increase the likelihood of adaptation. However, households with relatively big farm size affected SWC negatively at $1 \%$ significant level. One hectare of land addition would decrease the probability of SWC by $8.9 \%$. The probable reason for the result could because it needs more investment for SWC (stone bund, terracing, etc.) to use for big land. Also, it might be different characteristics of the large farm that demands different adaptation methods, therefore farm plot characteristics might not promising for SWC. Similar findings (Solomon et al., 2014; Adjaye et al., 2016) identified the probability of using adaptation to climate change decreases with larger plot size.

Livestock Ownership (Intlu): Livestock is expected to be one of insurance against climate change consequence. The result of the study showed that livestock ownership is found to affect positively the use of SWC practice at $1 \%$ significant level. The marginal effect of the result indicated that a one-unit increase in TLU leads to increases in the probability of SWC by 3.18\%. The result implies that having more livestock might strengthen and augment farmers' adaptive capacity for SWC from livestock income. Similar studies (Abrham et al., 2017; Seid et al., 2016, Solomon et al., 2014; Aemro et al., 2012; Apata, 2011) indicated that livestock owners used SWC and other strategies to minimize risks from climate change.

Oxen power- Innumboxen: Having oxen used as a means of plowing; having more oxen adversely affected intercropping adaptation strategy at 1\% significant level. Farmers who had one less number of oxen increased the probability of intercropping by $2.51 \%$. This implies the intercropping is oxen labour saving option and can be implemented manually that the option is mostly important for poor farmers.

Inassetvalue: Asset value is a proxy of a wealth of the farmer that significantly and positively affected stubble at $1 \%$ level and intercropping at 5\% significant level. A one Birr increase in wealth of the farmer leads increasing in the probability of choosing stubble by $1.59 \%$ and intercropping by $2.18 \%$. This implies that that more assets can help individuals to deal with the negative impacts of extreme climate change. There is evidence that types of assets play a fundamental role in explaining climate change risks (Abraham and Fonta, 2018). A similar study indicated that the economic capital index significantly and positively affected the water-use efficiency adaptation option in South Africa (Muthelo et al., 2019).

Inimprovedvar. Using more improved varieties helps to increase the likelihood of practicing different adaptation strategies to climate change. The results indicate that using different improved varieties positively associated with more choice of adaptation strategies (stubble, SWC, intercropping and rotation) at 1\% significant level while positively affected tree planting at 5\% significant level. The marginal effect result indicated that a unit increase in using variety increased the chance to adopt stubble $(8.13 \%)$, SWC $(9.62 \%)$, inter-cropping $(6.91 \%)$, planting a tree $(0.83 \%)$ and crop rotation $(20.04 \%)$. Using more adaptation options might be components of a package for crop technology to mitigate climate risk. The result is consistent with the findings of (Adjaye et al., 2016) that improved variety enhanced SWC and tree planting. 
Table 8 Determinants of farmers adaptive strategies

\begin{tabular}{|c|c|c|c|c|c|}
\hline \multirow[b]{2}{*}{ Variables } & \multicolumn{5}{|c|}{ Marginal Effect } \\
\hline & swcuse & intercrop & mulch & trees & interrot \\
\hline \multirow[t]{2}{*}{ sex } & $0.1829 * * *$ & 0.0622 & -0.0026 & 0.0056 & -0.1246 \\
\hline & $(0.0143)$ & $(0.0122)$ & $(0.0031)$ & $(0.006)$ & $(0.0123)$ \\
\hline lnage_hd & -0.0618 & 0.0274 & 0.0011 & -0.0075 & -0.0459 \\
\hline$(0.015)$ & $(0.0118)$ & $(0.0109)$ & $(0.0039)$ & $(0.0044)$ & $(0.0097)$ \\
\hline \multirow[t]{2}{*}{ lneduc_hd } & $0.0078^{*}$ & -0.0063 & $-0.0004^{*}$ & 0.0002 & -0.0055 \\
\hline & $(0.0011)$ & $(0.001)$ & $(0.0003)$ & $(0.0004)$ & $(0.001)$ \\
\hline \multirow[t]{2}{*}{ Inmalelabor } & 0.0108 & $0.0481 * *$ & -0.0004 & $-0.0041 * *$ & $0.1301 * *$ \\
\hline & $(0.005)$ & $(0.0046)$ & $(0.0019)$ & $(0.0014)$ & $(0.004)$ \\
\hline \multirow[t]{2}{*}{ Infemalelabor } & $-0.0166 * *$ & 0.0073 & 0.0006 & $-0.0014^{* *}$ & $0.0673^{* * *}$ \\
\hline & $(0.0019)$ & $(0.0017)$ & $(0.001)$ & $(0.0006)$ & $(0.0014)$ \\
\hline \multirow[t]{2}{*}{ lnfarmsize } & $-0.0893^{* * *}$ & 0.0161 & -0.0001 & -0.0038 & $0.2602 * * *$ \\
\hline & $(0.0059)$ & $(0.0053)$ & $(0.0019)$ & $(0.0021)$ & $(0.0048)$ \\
\hline \multirow[t]{2}{*}{ lntlu } & $0.0318 * * *$ & 0.0153 & 0.0009 & 0.0017 & -0.0249 \\
\hline & $(0.0028)$ & $(0.0025)$ & $(0.0013)$ & $(0.0013)$ & $(0.0024)$ \\
\hline \multirow[t]{2}{*}{ lnnumboxen } & 0.0012 & $-0.0251^{* * *}$ & 0.0003 & -0.0004 & 0.0127 \\
\hline & $(0.0018)$ & $(0.0016)$ & $(0.0007)$ & $(0.0006)$ & $(0.0015)$ \\
\hline \multirow[t]{2}{*}{ Inassetvalue } & 0.0122 & $0.0218 * *$ & 0.0001 & 0.0017 & 0.0169 \\
\hline & $(0.002)$ & $(0.0019)$ & $(0.0006)$ & $(0.001)$ & $(0.0014)$ \\
\hline \multirow[t]{2}{*}{ womenmember } & $0.1128 * * *$ & $-0.0816^{* *}$ & -0.0007 & 0.0023 & $-0.1832 * *$ \\
\hline & $(0.0085)$ & $(0.0079)$ & $(0.0028)$ & $(0.0027)$ & $(0.0072)$ \\
\hline \multirow[t]{2}{*}{ lnimprovedvar } & $0.0962 * * *$ & $0.0691 * * *$ & -0.0007 & $0.0083 * *$ & $0.2006^{* * *}$ \\
\hline & $(0.0067)$ & $(0.0053)$ & $(0.0014)$ & $(0.0029)$ & $(0.0046)$ \\
\hline \multirow[t]{2}{*}{ lnnumbext } & -0.0075 & 0.0163 & $0.0013^{*}$ & $0.0024^{*}$ & $-0.0639^{*}$ \\
\hline & $(0.0028)$ & $(0.0026)$ & $(0.001)$ & $(0.0012)$ & $(0.0028)$ \\
\hline \multirow[t]{2}{*}{ lndstmnmkt } & $-0.0179 * *$ & -0.007 & -0.0001 & 0.0001 & -0.0019 \\
\hline & $(0.0015)$ & $(0.0014)$ & $(0.0005)$ & $(0.0005)$ & $(0.0014)$ \\
\hline \multirow[t]{2}{*}{ Oromia } & -0.0601 & $-0.1706^{* *}$ & 0.0033 & 0.0035 & $-0.2647 * *$ \\
\hline & $(0.0102)$ & $(0.0094)$ & $(0.0038)$ & $(0.0035)$ & $(0.0103)$ \\
\hline \multirow[t]{2}{*}{ Bensha } & $-0.1593 * *$ & $-0.2621 * * *$ & 0.0044 & 0.0015 & -0.1108 \\
\hline & $(0.0205)$ & $(0.0184)$ & $(0.0054)$ & $(0.0076)$ & $(0.0203$ \\
\hline-0.039 & $-0.1711 * *$ & 0.0389 & -0.0216 & 0.0018 & -0.1832 \\
\hline$(0.0154)$ & $(0.0119)$ & $(0.0108)$ & $(2.0328)$ & $(0.0042)$ & $(0.0112)$ \\
\hline$-0.2895^{*}$ & -0.2477 & $-0.7153 * * *$ & $-0.0288 *$ & $-0.0422^{*}$ & 0.8364 \\
\hline$(0.0679)$ & $(0.0533)$ & $(0.0491)$ & $(0.0186)$ & $(0.0203)$ & $(0.0436)$ \\
\hline & $\sum$ swcuse*st $^{*}$ & $\sum$ intercrop*st & & & Einterrot*s \\
\hline Covariance matrix: Covariance & uble & & $\sum$ mulch*stuble & $\sum$ tree*stuble & tuble \\
\hline indicates the relationship between two & 0.0221 & $0.107 * * *$ & 0.135 & $0.280 * * *$ & $0.135^{* *}$ \\
\hline variables whenever one variable & $(0.0378)$ & $(0.0379)$ & $(0.136)$ & $(0.0871)$ & $(0.0563)$ \\
\hline changes. If an increase in one variable & $\sum$ intercrop & $\sum$ mulch*swc & & Einterrot* ${ }^{*}$ w & ¿mulch*int \\
\hline results in an increase in the other & *swcuse & use & $\sum$ tree*swcuse & cuse & ercrop \\
\hline variable, both variables are said to & 0.0565 & $0.603 * * *$ & $0.716 * * *$ & $0.152 * * *$ & -0.146 \\
\hline have positive covariance. Decreases in & $(0.0354)$ & $(0.181)$ & $(0.120)$ & $(0.0510)$ & $(0.138)$ \\
\hline $\begin{array}{l}\text { one variable also cause a decrease in } \\
\text { the }\end{array}$ & $\sum$ tree*inter & $\sum$ interrot*inte & $\Gamma$ tree*mulch & $\sum$ interrot*mu & $\sum$ interrot*tr \\
\hline together in the same direction when & 0.0311 & $1.361 * * *$ & $0.532 * * *$ & 0.0784 & 0.112 \\
\hline they change & $(0.0824)$ & $(0.188)$ & $(0.170)$ & $(0.158)$ & $(0.131)$ \\
\hline & swcuse*stu & intercrop*stu & & & interrot*stu \\
\hline & ble & ble & mulch*stuble & $\sum$ ree*stuble & ble \\
\hline & 0.0221 & $0.1065^{* * *}$ & 0.1345 & $0.2730^{* * *}$ & $0.1344 * *$ \\
\hline Correlation between equations & $(0.0377)$ & $(0.0374)$ & $(0.1336)$ & $(0.0806)$ & $(0.0553)$ \\
\hline (rho): The correlation coefficient & intercrop*s & mulch*swcus & & interrot*swcu & mulch*inte \\
\hline measures the robustness of the & wcuse & $\mathrm{e}$ & tree*swcuse & se & rcrop \\
\hline relationship between two variables. & 0.0564 & $0.5393 * * *$ & $0.6144 * * *$ & $0.1506^{* * *}$ & -0.1451 \\
\hline Pearson's correlation coefficient is one & $(0.0353)$ & $(0.1281)$ & $(0.0749)$ & $(0.0499)$ & $(0.1347)$ \\
\hline of the most commonly used & tree*intercr & interrot*inter & & interrot*mulc & interrot*tre \\
\hline correlation coefficients and measures & op & crop & tree*mulch & $\mathrm{h}$ & $\mathrm{e}$ \\
\hline the linear relationship between two & 0.0311 & $0.8767 * * *$ & $0.4867 * * *$ & 0.0783 & 0.1113 \\
\hline variables. & $(0.0823)$ & $(0.0434)$ & $(0.1299)$ & $(0.1573)$ & $(0.1296)$ \\
\hline
\end{tabular}

Calculate the correlation coefficient, $\rho$ rho $=$ cov_XY / (sigma_X*sigma_Y);

Frequency of extension contact (Innumbext). Access to extension agents is an important source of information on suitable adaptation options of climate change for farmers (Hassan and Nhemachena, 2008; Maddison, 2006). The result shows that access to extension services significantly increases the probability of mulching and tree 
planting at $10 \%$ significant level. A day increase in extension contact led to an increase in the probability of adaptation of mulching by $0.13 \%$ and tree planting by $0.24 \%$. This result implies that an increase in the number of extension visit to farmer creates more awareness about mulching and tree planting technology dissemination. The result is consistent with that of (Abrham et al., 2017; Serkalem et al., 2014; Owombo et al., 2014; Deressa et al., 2011). However, extension contact adversely affected the probability of crop rotation practices at $10 \%$ significant level. The marginal effect indicated that one additional day of extension contact reduced the probability of using crop rotation practices by $6.39 \%$. The extension system might much more concerned with other profitable adaptation options and dominate farmers' knowledge or practice of crop rotation that usually farmers use. The similar finding extension access negatively correlated with crop rotation (Ayuya et al., 2012).

Nearest market distance (Indstmnmkt): The nearest market expected to access information about climate adaptation strategies. Farmers who reside in the nearest market is significantly and positively correlated to stubble (at 5\% level) and SWC (at 1\% level). The one km less to the nearest market increases the probabilities of choosing stubble by $0.09 \%$ and SWC by $1.79 \%$. This implies that the nearest farmers have an opportunity to get information and might buy complementary technology for stubble and SWC. Similarly (Solomon et al., 2014) reported that nearest farmers to input/output market more chosen adaptation than the farthest farmers.

It is observed that different farmers living in different regions/agro-ecological settings (Oromia, Benshangul Gumuze, SNNP, and Amhara) apply different adaptation options since, having different climatic conditions, soil, and other factors to mitigate climate variability. The study computed the model using Amhara as a base category to compare the adaptation options in different regions. The following results are consistent with (Deressa et al., 2011; Aemro et al., 2012) that live in different agro-ecological settings; take up different adaptation options.

Oromia region (Oromia): The MVP regression analysis indicated that farmers live in Oromia appears to increase the likelihood of selecting stubble by $8.7 \%$ at $5 \%$ significance level while decreasing the probability of selecting intercropping by $17.06 \%$ at $1 \%$ and decreasing crop rotation by $26.47 \%$ at $5 \%$ significance level. These imply that being a resident in Oromia, as compared with farming/living in Amhara increases the probability of adapting stubble practice; whereas it reduces the probability of intercropping and crop rotation.

Benshangul Gu. region (Bensha): The result indicated that living in Benshangul-Gumuz region significantly and less likely to selecting stubble, SWC and intercropping at 1\%,5\%, and $1 \%$ level, respectively. Being farmers live in the region reduces the probability of adapting stubble by $18.46 \%$, SWC by $15.93 \%$ and intercropping by $26.21 \%$. This implies that being a resident in Benshangul, as compared to that of Amhara, decreases the probability of adopting the options.

Southern Nation Nationalities People region (SNNP): Living in SNNP lead to reduce the probability of choosing SWC at 5\% significant level. Being farmers live in SNNP region reduces the probability of adapting stubble by SWC (17.11\%) compared to that of Amhara region.

\subsubsection{The MVP regression result from $\mathrm{FHH}$}

The descriptive statistics indicated that climate adaptation strategies of $\mathrm{MHH}$ and $\mathrm{FHH}$ were different which might be due to access to resources, skill, and knowledge. The results of the descriptive analysis reveal that FHHs more adopted stubble, SWC and crop rotation adaptation options than MHHs. Similar findings support this result that women are disadvantaged in resources compared with the counterparts that lead them to low productive and limit adopt climate change adaption practices (Aguilar et al., 2014). Therefore empirical analysis was done on the entire sample and FHHs because the result for the whole sample and MHHs are the same. The study generates insights into the different adaptation strategies and multiple factors which differently influence FHH that of MHH (Table 9). 
Table 9 Determinants of women farmers adaptive strategies (MVP result)

\begin{tabular}{|c|c|c|c|}
\hline \multirow[b]{2}{*}{ Variables } & \multicolumn{3}{|c|}{ Marginal } \\
\hline & stuble & interro & swcuse \\
\hline \multirow[t]{2}{*}{ lnage_hd } & 0.083 & $-0.8424 * * *$ & 0.0304 \\
\hline & $(0.0706)$ & $(0.095)$ & $(0.0792)$ \\
\hline \multirow[t]{2}{*}{ lneduc_hd } & 0.0073 & $-0.0572 * *$ & 0.0065 \\
\hline & $(0.0071)$ & $(0.0080)$ & $(0.007)$ \\
\hline \multirow[t]{2}{*}{ lnmalelabor } & -0.015 & 0.0388 & 0.002 \\
\hline & $(0.0136)$ & $(0.0125)$ & $(0.0174)$ \\
\hline \multirow[t]{2}{*}{ lnfemalelabor } & 0.0197 & 0.0488 & $-0.0375^{*}$ \\
\hline & $(0.014)$ & $(0.0103)$ & $(0.0132)$ \\
\hline \multirow[t]{2}{*}{ lnfarmsize } & 0.0102 & 0.0399 & $-0.1112 * *$ \\
\hline & $(0.0269)$ & $(0.0276)$ & $(0.0327)$ \\
\hline \multirow[t]{2}{*}{ lntlu } & 0.0175 & 0.0073 & 0.0047 \\
\hline & $(0.0101)$ & $(0.0095)$ & $(0.0116)$ \\
\hline \multirow[t]{2}{*}{ lnnumboxen } & -0.0044 & 0.0292 & -0.0023 \\
\hline & $(0.0086)$ & $(0.0101)$ & $(0.01$ \\
\hline \multirow[t]{2}{*}{ lnassetvalue } & $0.0447 * *$ & -0.017 & $0.0499 * *$ \\
\hline & $(0.0162)$ & $(0.0079$ & $(0.0138)$ \\
\hline \multirow[t]{2}{*}{ womenmember } & $-0.1456 * *$ & -0.0224 & 0.0888 \\
\hline & $(0.053)$ & $(0.0458)$ & $(0.0496)$ \\
\hline \multirow[t]{2}{*}{ lnimprovedvar } & -0.0167 & 0.0467 & $0.1918 * *$ \\
\hline & $(0.0201$ & $(0.014)$ & $(0.0585)$ \\
\hline \multirow[t]{2}{*}{ lnnumbext } & -0.0164 & 0.0406 & 0.0177 \\
\hline & $(0.0116)$ & $(0.0125)$ & $(0.016)$ \\
\hline \multirow[t]{2}{*}{ lndstmnmkt } & -0.0014 & 0.0112 & 0.002 \\
\hline & $(0.0083)$ & $(0.0094)$ & $(0.0102)$ \\
\hline \multirow[t]{4}{*}{ Constant } & $-0.789 * *$ & $3.3956 * * *$ & $-0.9385^{*}$ \\
\hline & $(0.2986)$ & $(0.3588)$ & $(0.3342)$ \\
\hline & $\sum$ interrot*stuble & $\sum$ swcuse $^{*}$ stuble & $\sum$ swcuse $*$ interrot \\
\hline & $0.608^{* *}$ & 0.153 & $1.275 * * *$ \\
\hline \multirow[t]{3}{*}{ Covariance matrix $\left(\sum\right)$} & $(0.272)$ & $(0.175)$ & $(0.391)$ \\
\hline & interrot*stuble & swcuse*stuble & swcuse*interrot \\
\hline & $0.5424 * * *$ & 0.1515 & $0.8551 * * *$ \\
\hline Correlation between equations ( $\boldsymbol{\rho}$ ) & $(0.1918)$ & $(0.1710)$ & $(0.1051)$ \\
\hline
\end{tabular}

Age of household head (Inage_hd). The age of household head is used to capture farming and adaptation experience. However, the age of women head of the household is negatively affected crop rotation at $1 \%$ significant level. As the age of FHH increases by one year led to reducing the probability of crop rotation by $84.24 \%$. A reasonable explanation is those older women farmers more reluctant to use crop rotation than younger women farmers because old women were experienced on crop rotation but they might search for other better adaptation options.

Level of education of FHH- (Ineduc_hd). Educated households are expected to be more informed about climate change and respond positively. However, the education level of women head negatively and significantly affects crop rotation at 5\% level. Increase the level of education of FHH leads to a decrease in the probability of crop rotation practice of farmers by $5.72 \%$. The result might be crop rotation practice was most common for farmers in their locality so they choose other better climate adaption options at the expense of crop rotation.

Availability of female labour hour- equivalent to man hour (Infemalelabor):. Similar to the results in all sampled farmers' in this study, the availability of women labour negatively related to SWC at $10 \%$ significant level. A unit increase in women labour (man-hour) led to a decrease the probability of choosing SWC by $3.75 \%$. This might be due to gender role and responsibility, and cultural barriers in maize legume farming system; it might not allow women to engage in the SWC practices. The result above confirmed by several findings (Abayineh and Belay, 2017; Abrham et al., 2017; Birtukan and Abraham, 2017; Federica et al., 2016; Adjaye et al., 2016; Solomon et al., 2014; Belaineh et al., 2013; Deressa et al., 2011; Negash, 2014) that female farmers involvement in SWC was limited.

Women cooperative members in the household-(womenmember). Being membership in women group expected to exposes farmers to several ideas, information, training and extension services, which may enhance to change women farmers' attitudes toward new adaptation options. However, the result adversely and significantly affects stubble at $5 \%$ level. Being a women group in a household reduced the probability of choosing stubble by 
$14.56 \%$. The probable reason was collecting firewood is the responsibility of women that might limit to leave the leftover of the crop in the field, peculiarly maize stalk, and they broaden other adaptation opportunities to deal with climate change risk rather than chosen stubble.

Farm land size-(Infarmsize): Similar result of the whole sample in this study, there was a significant and negative relationship between farm size and SWC at 5\% level in FHHs. The result shows that increasing the size of land by one hectare reduced the probability of her choice of SWC by $11.12 \%$. This might be the larger land size require high investment to implement SWC and it might be SWC may not fit for all types of farmland. Similar results (Solomon et al., 2014; Adjaye et al., 2016) identified that farm size negatively and significantly associated with SWC.

Asset value of the household-(Inassetvalue): Asset value is the indication of the wealth status of the household that promising for responses for the climate changes, hence wealthier FHH are significantly capable to adopt stubble and SWC at 5\% level. As one Birr increase in asset value enhanced the women farmers' probability of adopting stubble by $4.47 \%$ and SWC by $4.99 \%$. This might be the wealthier women farmer could adapt both technologies (stubble and SWC) by covering related costs.

Number of improved varieties used in the household-(Inimprovedvar): adoption of improved variety significantly and positively associated with SWC at 5\% level. A unit increased use of improved variety would increase the probability of women farmers by $19.18 \%$. This implies that the adoption of improved variety requires SWC as complimentary technology. A similar finding indicated that improved varieties enhanced SWC (Adjaye et al., 2016).

\section{Conclusion and policy implication}

The study was aimed to identify gender differential adaption strategies for climate change, and their determinant factors in Maize-Legume Farming System in Amhara, Oromiya, and SNNP and Benshangul Gumuz regions of Ethiopia. The study used SIMLESA and DIIVA cross-sectional data. The study identified different adaptation strategies (stubble, soil, and water conservation (SWC), intercropping, mulching and tree planting) of farmers in the study areas.

The MVP results of the entire sample indicated that MHHs had more probability to use stubble and SWC than FHHs. These imply usually men had more information on the strategies than women. Old farmers were not convinced to use stubble; elders might not see the benefit of the new strategy, stubble. The education level of HHHs enhanced to use stubble and SWC strategies and negatively associated with mulching. Knowledge of farmers might enable them to analyze the benefit of each adaptation option and to choose the better option. Therefore adaptation strategies should be demand-driven, participatory and gender-responsive.

The availability of men labour in the HH significantly and positively enhanced intercropping and crop rotation. Women labour also had the probability of choosing stubble and crop rotation; but women labour was less likely to engage in SWC (terracing, soil bund, stone bund, etc); these might be due to gender role and responsibility in the household/society. Hence keeping social norm and values, and farmers' capability and interests are important to improve the specialization and sustainability of adaptation options. The availability of men and women labour were less likely to participate in tree planting; probably due to farmers' concern on the problem of crop damage by birds. This suggests promoting tree planting with complimentary options: chop and trim the tree during crop planting and maturity period.

Resource ownership (farm size, livestock, oxen and asset value) affected adaptation options. Farmers with more farmland size significantly and positively affected stubble and crop rotation that need less chemical; however farmers with large farm landholding adversely affected SWC; that might require high investment or SWC might not fit for the types of a specific plot. Having more livestock encouraged adapting SWC; it might be livestock serve as insurance to cover SWC related costs. Farmers with few oxen chosen intercropping, probably it is a costeffective adaption option particularly worthy for poor farmers. Farmers with high asset value adapted stubble and intercrop to deal with climate change. Based on the results it suggests provide location-specific, affordable and appropriate adaptation options to contribute to the best chance of success and sustainability of adaptation options.

Being a membership of women group negatively affected intercropping and crop rotation; the options might be staying for a long time in the farming system, but the group only promotes WSC. Farmers with more improved varieties enhanced to adopt five adaptation options; this indicates that crop technology and climate adaptation options are complimentary to increase production and productivity. Frequent contact with extension agents enhanced farmers to choose mulch and tree planting, but less extension contacted farmers chosen crop rotation; that might be extension focused on the new practices. Theses suggested climate change adaptation should be improved by strengthening extension service and social groups to scale-out recent and appropriate adaptation options. The extension system should be strengthening to include appropriate adaption strategies as one of the crop technology packages.

Farmers lived in the nearest market chosen stubble and SWC that might be farmers exposed for information; hence government should strengthen early warning systems at the village level which can help farmers' forecasting 
and increases their preparedness to adjust adaptation options. Farmers lived in different regions (Oromia, SNNP and Benshaangul Gumuz) used different adaptation options that might be due to different climatic conditions, soil, and other factors of agro-ecologic setting, therefore the government should support to provide research and agroecology based adaptation options to manage risks and maximize opportunities from climate change.

The existing differences in gender role and responsibly, access and control over resources, etc. lead FHHs more chosen different options (stubble, SWC, and crop rotation) than MHHs. The study reveals that age and education of FHHs significantly and negatively affected crop rotation. Crop rotation might be FHH farmers had enough experience and practiced for a long time in the farming system, encouraged to find other better adaptation options. These should be supported by investing and availing women-specific, appropriate and alternative adaptation options.

FHHs with more women labour discouraged to engage in SWC; that might be due to the role and responsibility of women in society to limit women members to participate in SWC activities. Therefore, keeping social norms is important by providing alternate adaptation options for women. Women farmers with more farmland less likely to choose SWC that might require high investment or SWC might not promise for specific plot story. Farmers with high asset value were able to choose stubble and SWC. Wealthier women farmers might be able to cover stubble and SWC related costs. Therefore the government should promote affordable and appropriate adaptation options for women.

Being a member of women farmers in cooperative significantly and negatively affected stubble; the adaptation option might compete with firewood availability that women are mostly responsible to collect firewood for the household. This suggests alternative or renewable energy sources should be made available to promote a stubble strategy. Using more improved crop variety increases the probability of women farmers' choosing SWC; the adaptation option might be complimentary for improved variety. Therefore, the extension system needs to improve the available packages by incorporating SWC to deal with climate change.

\section{Reference}

Abayineh Amare, Belay Simane, 2017. climate change induced vulnerability of smallholder farmers: Agroecology-based analysis in the Muger Sub-Basin of the Upper Blue-Nile Basin of Ethiopia. Amer. J of Climate Change, (6): 668-693.

Abrham Belay, Recha J.W, TeshaleWoldeamanuel and Morton J.F., 2017. Smallholder farmers' adaptation to climate change and determinants of their adaptation decisions in the Central Rift Valley of Ethiopia. Agric\& Food Secur (2017) 6:24 pp -13.

Abraham, T.F. and Fonta, M.W., 2018. Climate change and financing adaptation by farmers in northern Nigeria. Springer 4 (11): 1-17. https://doi.org/10.1186/s40854-018-0094-0.

Adjaye, J. Mallawaarachchi T., and ChilotYirga, 2016. Strategies for managing climate risk: a case study of smallholder farmers in Ethiopia J. of Agric. Econ and Rural Deve. Vol. 3(2): 91-104.

Aemro T, Jemma H., and MengistuK.,, 2012. Climate Change Adaptation Strategies of Smallholder Farmers: The Case of Babilie District, East Harerghe Zone of Oromia Regional State of Ethiopia. J. of Econ. and Sustainable Dev. 3 (14):1-13.

Aguilar A., Carranza E. Goldstein M. Kilic T. and sent G., 2014. Decomposition of Gender Differentials in Agricultural Productivity in Ethiopia. Policy Research Working Paper No. 6764. 54p.

Alston, M., 2014.Gender mainstreaming and climate change. Womens Stud. Int. Forum, 47, 287-294.

Akinnagbe O.M1 and Irohibe I. J. 2014. agricultural adaptation strategies to climate change impacts in Africa: a review Bangladesh J. Agril. Res. 39(3): 407-418.

Amogne Asfaw, Belay Simane, AmareBantider and Ali Hassen, 2018. Determinants in the adoption of climate change adaptation strategies: Evidence from rainfed-dependent smallholder farmers in north-central Ethiopia (Wolekasub-basin). Development studies research, 4 (1): 22-36.

Amisalu Milkias, 2018. The Role of Agronomic Practices on Soil and Water Conservation in Ethiopia; Implication for Climate Change Adaptation: A Review Journal of Agricultural Science; Vol. 10, No. 6; ISSN 1916-9752 E-ISSN 1916-9760. Published by Canadian Center of Science and Education.

Aschalew Shiferaw, 2014. Smallholder Farmers Adaptation Strategies to Climate Change in Ethiopia: Evidence from Adola RedeWoreda, Oromia Region. J. of Econ. and Sustainable Dev. 5,(7): 162-181.

Baćanović V. and Murić J. 2018. Gender and Climate Change. Training handbook. Pp57.

Belaineh Legesse, Yared Ayele and Woldeamlak Bewket, 2013. Smallholder farmers' perceptions and adaptation to climate variability and climate change in Boba District, West Hararghe, Ethiopia. Asian J. of Empirical Res. 3(3):251-265.

Biniam Debela, 2017. Gender and Climate Change: Determinants of Female Farmer's Adaptation Strategies to Climate Change; A Survey Study in Atsbi Womberta, Ethiopia. J. of Citizenship and Moralit, 1(1):14-40.

Birtukan Atinkut and Abraham Mebrat, 2016. Determinants of farmers' choice of adaptation to climate variability in Deraworeda, south Gondar zone, Ethiopia. Environmental Systems Research. 5(6) 1-8. 
Cappellari, L and Jenkins S.. 2003. Multivariateprobit regression using simulated maximum likelihood. The STATA Journal 3 (3): 278-294.

Cheng S. and Long J. S., 2007. Testing for IIA in the Multinomial Logit Model. Sociological Methods \& Research, 35(4): 583-600.

Deressa, Temesgen, Hassan R. M. and Ringler, C. (2011), Perception and Adaptation to Climate Change: The Case of Farmers in the Nile Basin of Ethiopia, The J. of Agri. Scie. (149): 23-31.

FAO, 2018. FAO'S work on climate change, United Nations.

FAO, 2012. Climate Change Adaptation and Mitigation in Agriculture.

FAO, 2011. The state of food and agriculture 2010-2011: Women in agriculture, closing the gender gap for development. 2011th ed., Rome, Italy.: Food and Agriculture Organization of the United Nations.

FAO, 2014 Adapting to climate change through land and water management in Eastern Africa.

Federica R., Berta M. L., Unai P., and Adam D., 2016. The diversity of gendered adaptation strategies to climate change of Indian farmers: A feminist intersectional approach. Ambio, Springerlink.com. pp 335-351.

Gebre Hadgu, KindeTesfaye, Girmamamo, and Belay Kasssa, 2015. Farmer's climate change adaptation options and their determinants in Tigrai Region, Northern Ethiopia. Afr. J. of Agri. 10(9): 956-964,

Golob T.F. and A.C. Regan. 2002. Trucking industry adoption of information technology: A multivariate discrete choice model. Transportation Research, C(10): 205-228.

Gutu Tesso, 2015. Is Adaptation to Climate Variability Gendered?, Evidence from a Developing Country, Ethiopia J. of Agri. and Ecology Res. Inte. 2(2): 92-104.

Hailemariam Teklewold, Alemu Mekonnen, and Kohlin, G. 2019. Climate change adaptation: a study of multiple climate-smart practices in the Nile Basin of Ethiopia. Climate and Development. 11(2): 180-192.

IFAD, 2018. The federal democratic republic of Ethiopia selected issues PP- 21.

IFAD, 2015. The Gender Advantage. Women on the front line of climate change. Pp-21. www.ifad.org

Hassan R, and Nhemachena C (2008). Determinants of African farmers' strategies for adapting to climate change: multinomial choice analysis. Afri. J. Agric. Res. Econs. 2(1): 83-104.

Lin, C-T.J., K.L. Jensen, and S.T. Yen. 2005. Awareness of foodborne pathogens among US consumers. Food Quality and Preference 16: 401-412.

Maddison, D. 2006. The perception of and adaptation to climate change in Africa. CEEPA. Discussion Paper No. 10.

Mahmud Yesuf, Falco Di S., Ringler C., Kohlin G., 2008. The Impact of Climate Change and Adaptation on Food Production in Low-Income Countries. Evidence from the Nile Basin, Ethiopia. IFPRI Discussion Paper 00828. Pp 24.

Menale Kassie, Zikhali, P. Kebede Manjur and Edwards S., 2008, Adoption of Organic Farming Technologies: Evidence from Semi-Arid Regions of Ethiopia, working papers No 335, pp 19.

Muthelo, D., Sekyere, O. E. and Ogundeji, A. A., 2019. Smallholder Farmers' Adaptation to Drought: Identifying Effective Adaptive Strategies and Measures. Water: 1-18. www.mdpi.com/journal/wate

Nabikolo, D. Bashaasha, B. Mangheni M.N. and Majaliwa J.G.M, 2012. Determinants of climate change adaptation among male and female. Headed farm households in eastern Uganda. Afri Crop Scie. J. l(20): 203 $-212$.

Negash M., 2011. Determinants of farmers' preference for adaptation strategies to climate change: evidence from north shoa zone of Amhara region Ethiopia. MPRA Paper No. 48753. Pp 1-11.

Owombo P.T., Koledoye G.F. Ogunjimi, S.I. Akinola A.A., Deji O.F. and Bolarinwa O., 2014. Farmers adaptation to climate change in Ondo State, Nigeria: A gender analysis. J. of Geog and Reg. Planning. 7(2): 30-35.

Rathgeber, E. M. 2011. Rural Women's Access to Science and Technology in the Context of Natural Resource Management. Paper presented in Expert Group Meeting, Enabling rural women's economic empowerment: institutions, opportunities and Participation, Accra, Ghana, 20-23 September 2011.

Seid Sani, Jema Haji and DegyeGoshu, 2016. Climate Change Adaptation Strategies of Smallholder Farmers: The Case of Assosa District, Western Ethiopia. J. of Env. and Earth. 6 (7):9-15.

Serkalem Getachew, Temesgen Tilahun and Misganaw Teshager, 2014. Determinants of Agro-pastoralist Climate Change Adaptation Strategies: Case of Rayitu Woredas, Oromiya Region, Ethiopia. Resh J.of Env. Sci. 8 (6): 300-317.

Solomon B., Agwata J. and *, Anyang S. 2014. Determinants of Adoption Choices of Climate Change Adaptation Strategies in Crop Production by Small Scale Farmers in Some Regions of Central Ethiopia. J. of Natural Sci. Res.4(4): 78-93.

Tesfamichael Wossen, 2016. Gender-Differentiated Impacts of Climate Variability in Ethiopia. A MicroSimulation Approach. Environment for Development Discussion Paper Series; EfD DP 16-24.

UNDP, 2017. Gender, climate change and food security. Training module 3.

UNDP, 2012 Gender and climate change. Training module 1. pp 40.

Wondimagegn Tesfaye. and Lemma Zemedu, 2015. Climate change perception and choice of adaptation strategies 
Empirical evidence from smallholder farmers in East Ethiopia. Int. J. of Climate Change Strategies and Management. 8(2):253-270. 